\title{
Drug reaction with eosinophilia and systemic symptoms (DRESS) syndrome in pediatrics. Clinical case
}

\section{Síndrome de sensibilidad a fármacos con eosinofilia y síntomas sistémicos en pediatría. Caso clínico}

\author{
Marcos Silva-Feistner ${ }^{a}$, Elena Ortiz ${ }^{a}$, María Jesús Rojas-Lechuga ${ }^{b}$, Daniel Muñoz $^{a}$
}

aDepartment of Dermatology, Pontificia Universidad Católica de Chile, Santiago, Chile

bontificia Universidad Católica de Chile, Santiago, Chile

Recibido el 20 de noviembre de 2015; aceptado el 30 de mayo de 2016

\begin{abstract}
Introduction: Drug reaction with eosinophilia and systemic symptoms (DRESS) is a potentially lifethreatening, drug-induced hypersensitivity reaction that includes skin eruptions, fever, lymphadenopathy, hematological abnormalities, and internal organ involvement. Objective: To present a rare condition in children; to facilitate a rapid diagnostic suspicion and recognition by doctors. Case report: A 9 months old infant admitted due to a severe viral pneumonia, treated with non-invasive ventilation and ceftriaxone, among other medications. Five days after stopping antibiotics, a violetcolored maculopapular rash appeared, confluent predominantly in the trunk, face and upper extremities, combined with a fever, eosinophilia, and elevated transaminases. She was treated with oral prednisone and topical corticosteroids for 6 weeks, with good results at 3 months follow-up. Conclusions: The diagnosis of DRESS syndrome is made using clinical criteria and laboratory examinations, as well as a skin biopsy in the case of any doubt in the diagnostics. Although it is most frequently caused by anticonvulsants, many other drugs have been implicated. Management consists of discontinuing the suspected drug associated with the reactions and a prolonged treatment of corticosteroids.
\end{abstract}

\section{Keywords:}

Drug reaction with eosinophilia and systemic symptoms; Drug-induced hypersensitivity reaction; Ceftriaxone; Paediatrics.

\section{Introduction}

A clinical presentation of exanthema associated with fever and lymphadenopathy represents a diagnostic challenge for a physician in terms of etiology, whether viral or drug-related. A high degree of suspicion should be given to this situation and a broad spectrum of differential diagnoses should be used, since adverse skin reactions to drugs are life-threatening, and an accurate diagnosis can affect the patient's prognosis.

Severe, adverse skin reactions to medications are less frequent in children than in adults, but potentially severe, with a mortality rate estimated at $10 \%$ for DRESS syndrome, 1-5\% for Stevens-Johnson syndrome, $25-30 \%$ for toxic epidermal necrolysis and less 
than $5 \%$ in generalized exanthemic pustulosis, with a high rate of complications and/or sequelae'.

Drug reaction with eosinophilia and systemic symptoms syndrome is a severe reaction caused by a hypersensitivity to drugs and/or its active metabolites, characterized by exanthema, fever, lymphadenopathy, hematological alterations and internal organ involvement $^{2}$. Its rate of occurrence is unknown, being reported more frequently in adults, without a differentiation between sexes. A risk is estimated in the population between $1 / 1,000$ and $1 / 10,000$ when exposed to a $\operatorname{drug}^{3,4}$.

The factors most frequently associated with DRESS are anticonvulsants (carbamazepine, lamotrigine, phenobarbital, phenytoin, valproic acid and zonisamide) in up to $35 \%$ of cases, alopurinol in $18 \%$, sulphonamides (sulfasalazine) and dapsone in $12 \%$ and other antibiotics in $11 \%{ }^{5,6}$. Initially, the condition was referred to as anticonvulsant hypersensitivity syndrome, due to its occurrence in relation to the use of these drugs; however, the diagnosis was extended to DRESS, since many other medications have been implicated ${ }^{7,8}$.

The objective of this manuscript is to present a rare condition in pediatrics, to facilitate diagnostic suspicion and rapid recognition by physicians.

\section{Clinical case}

An extremely premature female infant with mild bronchopulmonary dysplasia without oxygen dependency and hyaline membrane disease, requiring 2 doses of surfactant for treatment.

The patient was hospitalized at 9 months of age for adenovirus and parainfluenza virus 3 pneumonia, which required noninvasive mechanical ventilation in the pediatric intensive care unit; patient received Ceftriaxone (completed 7 days of treatment), methadone and palivizumab (a dose of $15 \mathrm{mg} / \mathrm{kg} \mathrm{IM}$ ).

Following the antibiotic treatment, at the twelfth day of hospitalization and the fifth day after ceftriaxone suspension, the patient developed isolated, febrile elevations up to $38^{\circ} \mathrm{C}$, without hemodynamic compromise, associated with a violaceous maculopapular rash. The exanthema began in the trunk, approaching the upper limbs and face; then became confluent and generalized, after which fine scaling and facial edema appeared. There was neither mucosal involvement nor palpable lymphadenopathy (Figures 1 and 2).

Laboratory tests showed a normal white blood cell count $(5,910)$, with an absolute lymphocyte count of 3,110 (normal value [NV] 1.2-3) and an eosinophilia of $10.5 \%(620.5 / \mathrm{mm})(\mathrm{NV} 2.0-4.0 \%)$. Associated with this, she presented elevated transaminases, with glutamic-pyruvic transaminase (GPT) 593 (NV 4-41),

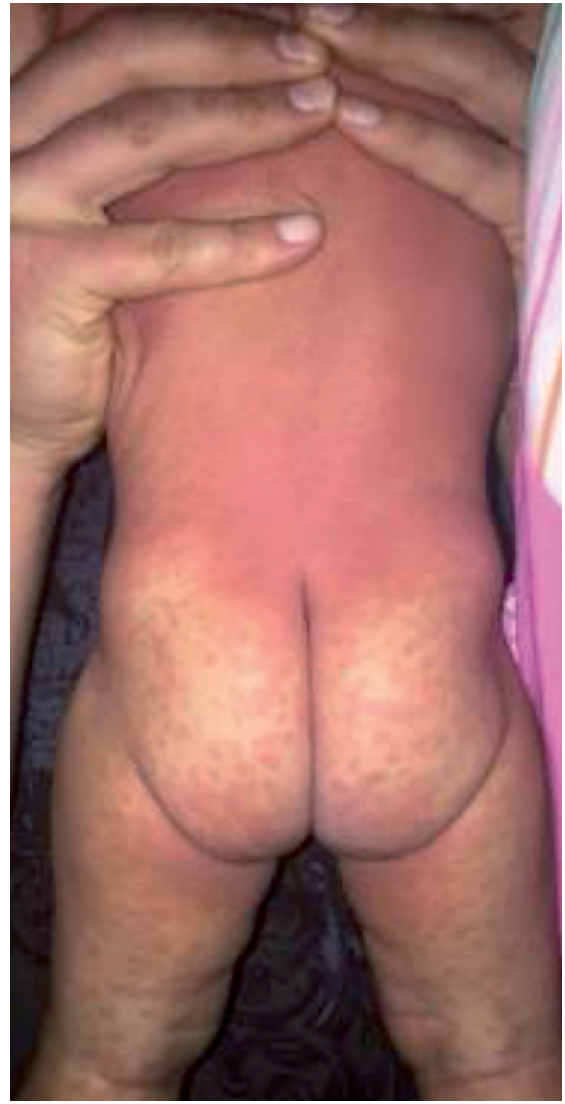

Figure 1.

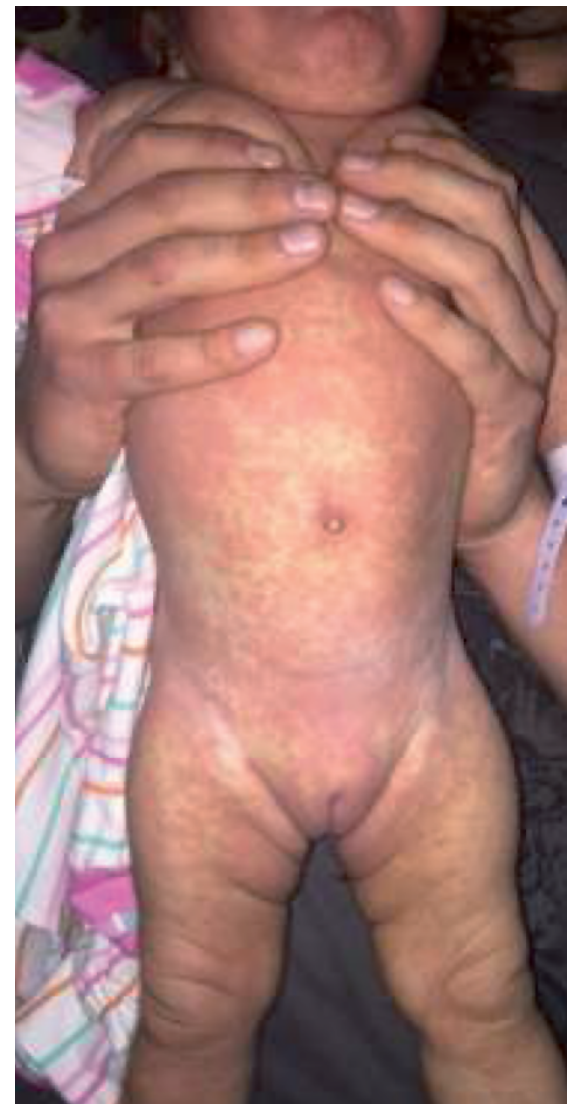

Figure 2. 
glutamic oxalacetic transaminase 531 (NV 9-37), gamma glutamyl transpeptidase 97 (NV 8-61) and alkaline phosphatase 157 (NV 40-129), with a total bilirubin of 0.34 (NV 0-1.00). Tests also presented negative blood cultures, normal renal function and a chest X-ray compatible with viral pneumonia, without evident condensation accumulation.

Through a dermatology evaluation, it was classified as DRESS, probably caused by ceftriaxone. It was treated with prednisone at a dose of $1 \mathrm{mg} / \mathrm{kg} / \mathrm{day}$, antihistamines, skin lubrication and a low potency topical corticosteroids. The patient responded favorably, with the disappearance of exanthema and correction of laboratory parameters (eosinophilia and liver tests).

Two weeks after discharge, she again presented a maculopapular exanthema associated with a fever up to $38^{\circ} \mathrm{C}$, without other symptoms. On the suspicion of a reactivation of DRESS syndrome, she was hospitalized in the special care unit, where tests were carried out, showing leukocytosis of 11,420 (NV 5.0-10.0) with eosinophilia $16.8 \%(1,918 \mathrm{~mm})$, Thrombocytosis 684,000 (NV 150-450), mild elevation of transaminases: GPT 70, glutamic oxalacetic transaminase 42 , gamma glutamyl transpeptidase 113, lactate dehydrogenase 224, preserved renal function and low inflammatory parameters.

In the context of the second hospitalization, a detailed diagnostic study was performed for clinical diagnosis, finding immunoglobulins $\mathrm{G}$ and $\mathrm{M}$ positive for cytomegalovirus. The presence of other viruses such as hepatitis $\mathrm{B}$ and $\mathrm{C}$ virus, human immunodeficiency virus, lues, mycoplasma infection and Ebstein-Barr viruses were ruled out; serology for herpes virus 6 (VH6) was not requested and a skin biopsy was not taken.

The diagnosis was interpreted as a reactivation of DRESS syndrome associated with a cytomegalovirus reactivation. It was managed with an oral prednisone regimen at a dose of $1 \mathrm{mg} / \mathrm{kg} /$ day, with a subsequent slow decrease ( 6 weeks), associated with topical corticosteroids. The patient presented a favorable recovery, with no new relapses at the 3 months follow up.

\section{Discussion}

DRESS syndrome is characterized by a latency of 2 weeks to 3 months between exposure to the drug and the development of the condition, with a lengthy recovery process despite drug discontinuation ${ }^{7,9,10}$.

Its etiopathogeny is proposed as a severe hypersensitivity to drugs and/or the subsequent active metabolites, which could be associated with an enzymatic defects in the metabolism of the drug. The exact mechanism of this reaction is unknown; type IV hypersensitivity has been proposed, but viral infections, particularly herpesvirus 6, have played a role in its pathogenesis ${ }^{6}$. Ahluwalia et al. studied in a cohort of 29 pediatric patients the relationship between VH6 and DRESS syndrome and demonstrated only 4 cases with VH6 positive, and in these they found a greater severity of the course of the disease and a greater frequency of pulmonary complications. It was also found to be associated with reactivation of other herpes viruses, including herpes virus 7, Epstein-Barr virus and cytomegalovirus $^{6}$. On the other hand, relationships have been established between certain HLA haplotypes and a predisposition to develop DRESS syndrome with some drugs, and specific mutations have been described in genes that code for detoxifying enzymes ${ }^{7}$.

It usually presents with non-specific prodrome; it can exhibit fatigue and fever, associated with a maculopapular morbilliform rash, which is present in $95 \%$ of patients, starting in the face and upper trunk and then becoming confluent and generalized. Exanthema should be suspicious if it compromises more than $50 \%$ of body surface area and includes 2 or more of the following clinical manifestations: facial edema, desquamation and purple colored ${ }^{5}$. About $50 \%$ of patients may present increase of volume and pain that can compromise a mucosa, but without evolving into erosions ${ }^{11}$.

To help the clinical diagnosis of DRESS syndrome, different criteria still has no consensus. Bocquet et al. presented 3 diagnostic criteria: skin eruption plus hematological abnormality and systemic compromises, including, as a hematological abnormality, eosinophilia $\geq 1,500$ or with presence of atypical lymphocytes, and as systemic compromises, adenopathy $\geq 2 \mathrm{~cm}$, hepatitis with transaminases $\geq 2$ times the normal value, interstitial nephritis, interstitial pneumonitis or carditis. The European Register of Severe Cutaneous Adverse Reactions developed a diagnostic table, expanding the criteria of Bocquet et al. ${ }^{12}$, which was based on clinical findings, extent of skin lesions, internal organ involvement and clinical course; according to this, each finding is classified as definitive, probable or possible $^{1}$ (Table 1). On the other hand, the Japanese Research Committee on Severe Cutaneous Adverse Reaction presented another set of diagnostic criteria, including the importance of VH6 in its etiopathogenesis, and classified according to a score of 7 for a typical DRESS syndrome and only a score of 5 for criteria that are considered an atypical DRESS ${ }^{7}$ (Table 2).

Differential diagnosis should be made with other severe skin rashes from drugs, bacterial, viral, lymphoma, and connective tissue diseases. Among the main ones to be ruled out, due to their severity, are StevensJohnson Syndrome, toxic epidermal necrolysis, generalized exanthemic pustulosis, hypereosinophilic syndromes, angioinmunoblastic T-cell lymphoma, 
Tabla 1. Criterios diagnósticos RegiSCAR para síndrome DRESS

\begin{tabular}{lcc}
\hline Ítem & Presente & Ausente \\
\hline Fiebre $>38,5^{\circ} \mathrm{C}$ & 0 & -1 \\
Adenopatías $(>1 \mathrm{~cm})$ & 1 & 0 \\
Eosinofilia $\geq 7000 \geq 10 \% / \geq 15000 \geq 20 \%$ (leucopenia) & 1 & 2 \\
Linfocitos atípicos & 1 & 0 \\
Rash $\geq 50 \%$ superficie corporal & 1 & 0 \\
Rash sugerente $(\geq 2$ de edema facial, púrpura o descamación) & -1 & 0 \\
Biopsia de piel sugerente diagnóstico alternativo & 1 & 2 \\
Compromiso de órganos internos: un órgano/2 o más & 0 & -2 \\
Duración de la enfermedad $>15$ días & 1 & 0 \\
Estudio de causa alternativa: $(\geq 3$ realizados y negativos). Hemocultivos, ANA, virus hepatitis, & 1 \\
micoplasma, clamidia & 1 \\
\hline
\end{tabular}

Puntaje total: $<2$ excluye, 2-3 posible, 4-5 probable, $\geq 6$ definitivo. Fuente: obtenido de Kardaun et $a^{5}$.

Sézary's syndrome and acute cutaneous lupus erythematosus ${ }^{13}$.

In suggestive clinical cases, the study should include hemogram, VHS, PCR, liver tests, chest X-ray, blood culture, VH6 and serology for hepatitis A, B and $\mathrm{C}$ virus, Epstein Barr virus and cytomegalovirus; IgM or PCR mycoplasma may also be included. In cases of diagnostic doubt, a skin biopsy can be performed, which can guide the diagnosis even though it is not pathognomonic ${ }^{13}$.

In the blood count of a patient with DRESS syndrome, it is possible to find eosinophilia $>700 \mathrm{~mm}$ in $50-90 \%$ of the cases, atypical lymphocytes, lymphoblasts or a pattern similar to infectious mononucleosis. It also shows increased GPT in about $80 \%$ of cases and infection with herpes virus in $40-60 \%$ of cases. It may result in palpable lymphadenopathy and multiple organ dysfunction. The liver is the most commonly affected organ, and it is associated with greater severity and mortality, shown in Table 2. Renal failure and lung involvement may also occur. Less frequent is cardiac failure secondary to myocarditis, neurological symptoms such as meningitis or encephalitis, gastroenteritis, pancreatic disorders and thyroid dysfunction ${ }^{2}$.

Exanthema and visceral compromise are gradually resolved once the drug is discontinued, with an average of 6 to 9 weeks. In 20\% of cases the disease may persist for an extended period, along with periods of remission and reactivation ${ }^{1,14}$.

For treatment, early identification and suspension of the causal drug is essential. Support measures and fluid/electrolyte balance should be implemented in cases of extensive cutaneous involvement. The most widely accepted treatment is systemic corticosteroids

\section{Tabla 2. Criterios diagnósticos J-SCAR para síndrome DRESS}

Desarrollo rash maculopapular $>3$ semanas luego del inicio del fármaco sospechoso

Persistencia de los síntomas luego de la descontinuación de la droga sospechosa

Fiebre $>38^{\circ} \mathrm{C}$

Alteraciones hepáticas (ALT > $100 \mathrm{U} / \mathrm{l}$ ) o compromiso de otro órgano

Anormalidad en glóbulos blancos $(\geq 1)$

Leucocitosis (>11'10\%/)

Linfocitos atípicos (> 5\%)

Eosinofilia $\left(>1,5,10^{9} / \mathrm{l}\right)$

Adenopatías

Reactivación VH6

Puntaje total: $7=$ DRESS típico, $5=$ DRESS atípico, $<5=$ considerar otro. Fuente: obtenido de Husain et $\mathrm{al}^{7}$.

for an extended period and with a gradual decrease to avoid relapses ${ }^{15}$. However, other treatment regimens, such as the use of topical corticosteroids, have been proposed in mild to moderate cases without systemic involvement. In those moderate to severe patients the evidence is controversial; Funck-Brentano et al. conducted a retrospective study of 38 patients, in which they concluded that the use of systemic corticosteroids is associated with greater complications such as viral reactivation, sepsis and mortality. However, in severe cases with renal and/or pulmonary compromise, benefits have been described, suggesting that it should be reserved only for severe cases; nevertheless, further studies and prospective evaluations are required to determine its usefulness and safety ${ }^{16}$. 
Our patient presented a clinical picture compatible with DRESS syndrome with hepatic impairment, along with laboratory tests that support the diagnosis. However, the clinical presentation with the suspect drug was 12 days, but registered in the literature as a latency of 2 to 12 weeks, without consensus.

In this case, certain background information that would have complement the study, such as the presence of atypical lymphocytes, the presence of herpes virus 6 and an eventual cutaneous biopsy, were lacking. Although, in accordance to the European Register of Severe Cutaneous Adverse Reactions diagnostic criteria it is considered "highly probable" of DRESS syndrome, the Japanese Research Committee on Severe Cutaneous Adverse Reaction would classify it as an "atypical" DRESS syndrome. The evolution of the relapsed cytomegalovirus associated with a response to corticosteroid therapy supports our diagnostic suspicion, and the prompt diagnosis and treatment avoided possible serious consequences.

\section{Conclusion}

DRESS syndrome is a rare entity in pediatrics. For this reason and for its potential severity, it is a diagnosis that should be considered in children who exhibit exanthema, fever, lymphadenopathy and systemic compromise. Although the most frequent cause is anticonvulsants, cases have been described for several drugs of different nature. The diagnosis is clinical, supported by laboratory tests, and can be supplemented with a skin biopsy in the case of diagnostic doubt. First of all, the management of these patients consists of suspending suspected drugs and implementing supportive measures. Regarding pharmacological treatment, the use of systemic corticosteroids for a prolonged period with a gradual decrease is suggested, so as to avoid relapses.

\section{Ethical Responsibilities}

Protection of people and animals: The authors state that no experiments have been performed on humans or animals for this research.

Confidentiality of data: The authors state that no patient data appears in this article.

Privacy rights and informed consent: The authors state that no patient data appears in this article.

\section{Conflict of interests}

The authors declare that they have no conflict of interest.

\section{References}

1. Belver MT, Michavila A, Bobolea I, Feito M, Bellón T, Quirce S. Severe delayed skin reactions related to drugs in the paediatric age group: A review of the subject by way of three cases (Stevens-Johnson syndrome, toxic epidermal necrolysis and DRESS). Allergol Immunopathol. 2016;44:83-95.

2. Rabenkogo A, Vigue MG, Jeziorski E. Le syndrome DRESS: une toxidermie à connaître. Arch Pediatr. 2015;22: 57-62.

3. Chi Chiou CC, Yang LC, Hung SI, et al. Clinicopathological features and prognosis of drug rash with eosinophilia and systemic symptoms; a study of 30 cases in Taiwan. J Eur Acad Dermatol Veneorol. 2008;22:1044-9.

4. Mockenhaupt M. Severe drug-induced skin reactions: Clinical pattern, diagnostics and therapy. J Dtsch Dermat Ges. 2009;7:142-60.

5. Kardaun SH, Sekula P, Valeyrie-Allanore $\mathrm{L}$, et al. Drug reaction with eosinophilia and systemic symptoms (DRESS): An original multisystem adverse drug reaction. Results from the prospective RegiSCAR study. Br J Dermatol. 2013;169:1071-80.

6. Ahluwalia J, Abuabara K, Perman MJ, Yan AC. Human herpesvirus 6 involvement in paediatric drug hypersensitivity syndrome. Br J Dermatol. 2015;172:10905.

7. Husain Z, Reddy BY, Schwartz RA. DRESS syndrome. Part I. J Am Acad Dermatol. 2013;68:693.

8. Teng P, Tan B. Carbamazepine-induced DRESS syndrome in a child: Rapid response to pulsed corticosteroids. Dermatol Online J. 2013;19:18170.

9. Descamps V, Mardivirin L, Janela B, Musette P, Ranger-Rogez S. Le syndrome d'hypersensibilité (DRESS) n'est qu'une maladie virale. Rv Fr Allergol. 2010;50:171-3.

10. Autret-Leca E, Norbert K, BensoudaGrimaldi L, et al. [DRESS syndrome, a drug reaction which remains bad known from paediatricians]. Arch Pediatr. 2007;14:1439-41 [Article in French].

11. Kardaun SH, Sidoroff A, ValeyrieAllanore L, et al. Variability in the clinical pattern of cutaneous side-effects of drugs with systemic symptoms: Does a DRESS syndrome really exist? Br J Dermatol. 2007;156:609-11.

12. Bocquet H, Bagot M, Roujeau JC. Druginduced pseudolymphoma and drug hypersensitivity syndrome (drug rash with eosinophilia and systemic symptoms: DRESS). Semin Cutan Med Surg. 1996;15:250-7.

13. Roujeau JC. Drug reaction with eosinophilia and systemic symptoms (DRESS). 2014;24. UptoDate.

14. Mardivirin L, Valeyrie-Allanore L, Branlant-Redon E, et al. Amoxicillininduced flare in patients with DRESS (drug reaction with eosinophilia and systemic symptoms): Report of seven cases and demonstration of a direct effect of amoxicillin on human herpesvirus 6 replication in vitro. Eur J Dermatol. 2010;20:68-73.

15. Husain Z, Reddy BY, Schwartz RA. DRESS syndrome. Part II. J Am Acad Dermatol. 2013;68:709.

16. Funck-Brentano E, Duong TA, Bouvresse $S$, et al. Therapeutic management of DRESS: A retrospective study of 38 cases. J Am Acad Dermatol. 2015;72:246-52. 